\title{
Subclavian aneurysm-tracheal fistula presenting with massive hemoptysis, a diagnostic dilemma to the emergency room personnel - A case report
}

\author{
Logn Falsk* \\ Blekinge Hospital, Department of Vascular Surgery, Karlskrona, Sweden
}

\begin{abstract}
Introduction: Subclavian aneurysm presenting as a massive hemoptysis has never been reported in the literature, the aim of the current study is to report for the first time, subclavian aneurysm-tracheal fistula presenting with massive hemoptysis.

Case report: A 56-year-old female presented with massive hemoptysis which was aggravated in the last two days. The patient was known case of TB received antituberculosis and cured. General examination showed pallor. Chest X-ray, CT scan and bronchoscopy was normal. Subclavian conventional angiography showed a fistula between left proximanl subclavian artery aneurysm and upper part of the trachea. After stabilization, the patient underwent operation, ligation of the right proximal subclavian artery, division, and transposition of the subclavian artery to the left bracheocephalic trunk.

Conclusion: Subclavian aneurysm-tracheal fistula presenting with massive hemoptysis has been reported for the first time in the literature. It presented as a diagnostic dilemma to the emergency room personnel.
\end{abstract}

\section{Introduction}

Hemoptysis is not infrequent presentation to the both medical and surgical emergency department. It is accounted for about $2 \%$ of the admitted cases in the acute setting [1]. Although there is no international consensus regarding categorization, hemoptysis can be classified into mild, moderate and massive according to the frequency of the symptom and amount of the blood expectorated in each time [2]. The causes are plenty including malignancy, infection and inflammatory diseases like wegner granulomatosis, good pasture syndrome and other connective tissue diseases. The diagnosis is not always straight forward [3]. The managing physicians may not be able to differentiate hemoptysis from hematamesis especially when the amount of the blood is too much. Investigations includes sputum examination, computed tomography, flexible and sometime rigid bronchoscopy. The patient may die from suffocation if not treated timely and correctly. Intubation and general anesthesia may be indicated in specific situations in which the patient complains from the suffocation and asphyxia [4].

Spontaneous fistula between aneurismal part of the great vessels between and the treacheobroncheal trees is extremely rare. Fitula between subclavian aneurysm and the treachia as a cause of massive hemoptysis has never been reported in the literature [5]. The aim of this report is to report the first case of massive hemoptysis presenting to the emergency department caused by spontaneous fitula between subclavian aneurysm and the trachea.

\section{Case report}

A 56-year-old female presented to the medical emergency department for management of massive hemoptysis which was present for one month and became worse in the last two days. The patient was known case of TB before 18 months for which he received antituberculosis and cured. The color of the expectoration was bright red and come in gush. The patient complained from three attacks per day. General examination showed pallor, normal chest and abdominal examination. Blood pressure on presentation was $110 / 80 \mathrm{mmHg}$, pulse rate 75 beats per minutes, respiratory rate was 18 beat per minutes, $\mathrm{SPO}_{2}$ was $96 \%$. Chest X-ray, CT scan and bronchoscopy was normal (Figures 1 and 2). The patient remained the medical department for 5 days without proper diagnosis, he was referred to the surgical emergency room for possibility of the operation if he has continuous massive hemoptysis, at surgical ward remained for 3 days, later deteriorated, intubated and admitted in ICU for 5 days, later discharged to ward, subclavian conventional angiography was performed and showed a fistula between left proximanl subclavian artery aneurysm and lower part of the trachea (Figure 3)! After stabilization and remaining in ward for 3 days, the patient underwent left posterolateral thoracotomy, ligation of the proximal subclavian artery, division, and transposition of the subclavian artery to the left bracheocephalic trunk was performed (Figure 4). Two proximal branches of the subclavian arteries were ligated, namely lateral thoracic artery and thoracoarcomial artery. The patient was discharged home in the $4^{\text {th }}$ post-operative days.

${ }^{\star}$ Correspondence to: Logn Falsk, MD, Blekinge Hospital, Department of Vascular Surgery, Karlskrona, Sweden, Tel: 00467234652; Fax: 105157247950; E-mail: lognfalsk1@gmail.com

Key words: subclavian aneurysm, fistula, hemoptysis

Received: November 02, 2018; Accepted: November 26, 2018; Published: November 29, 2018 


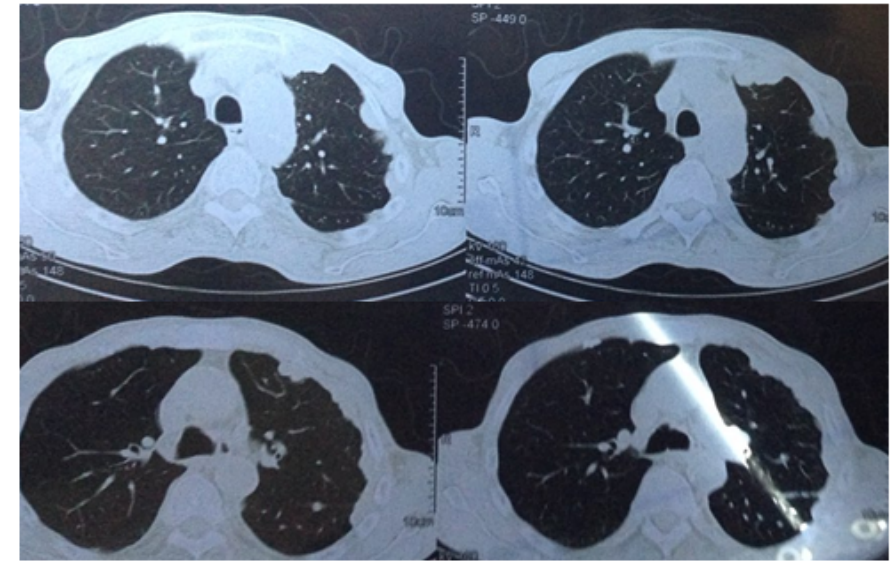

Figure 1. Computed tomography scan of the chest (sagittal section) does not showed signification findings

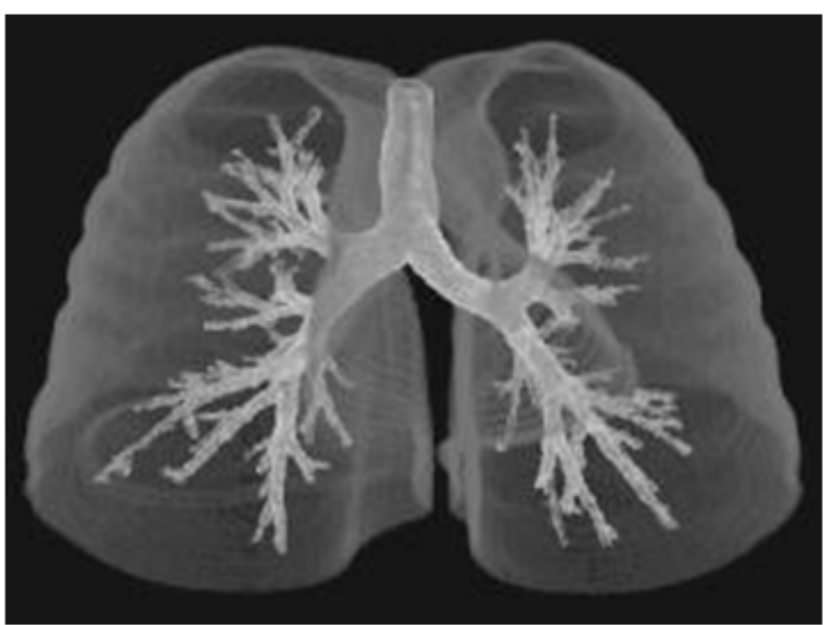

Figure 2. Detailed bronchoscopy showed no significant findings

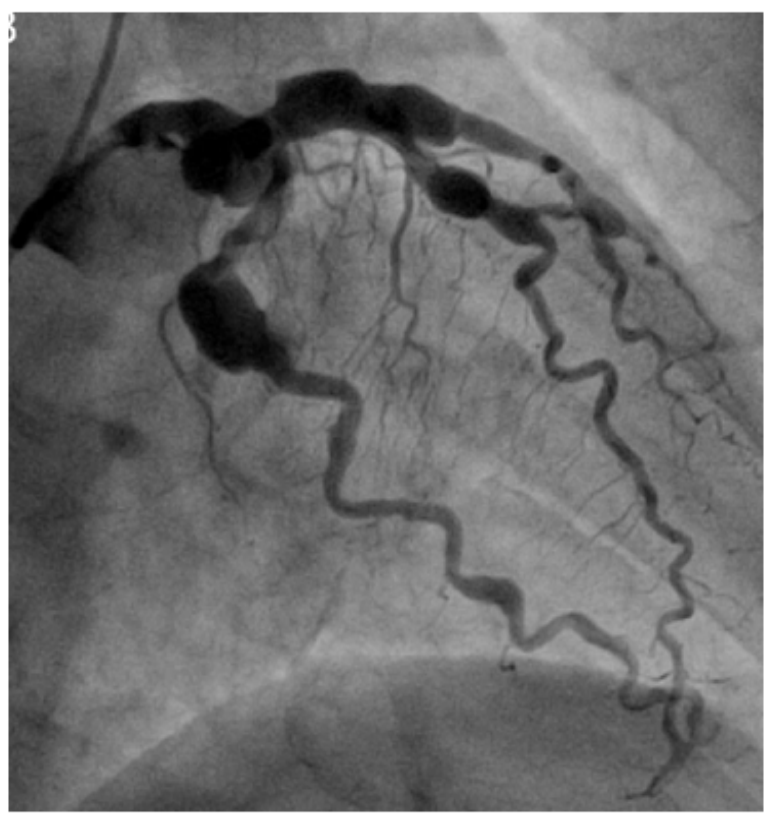

Figure 3. Conventional angiography of the left subclavian artery (Shakhawan view) showing aneurismal dialatation of the left subclavian artery and its branches

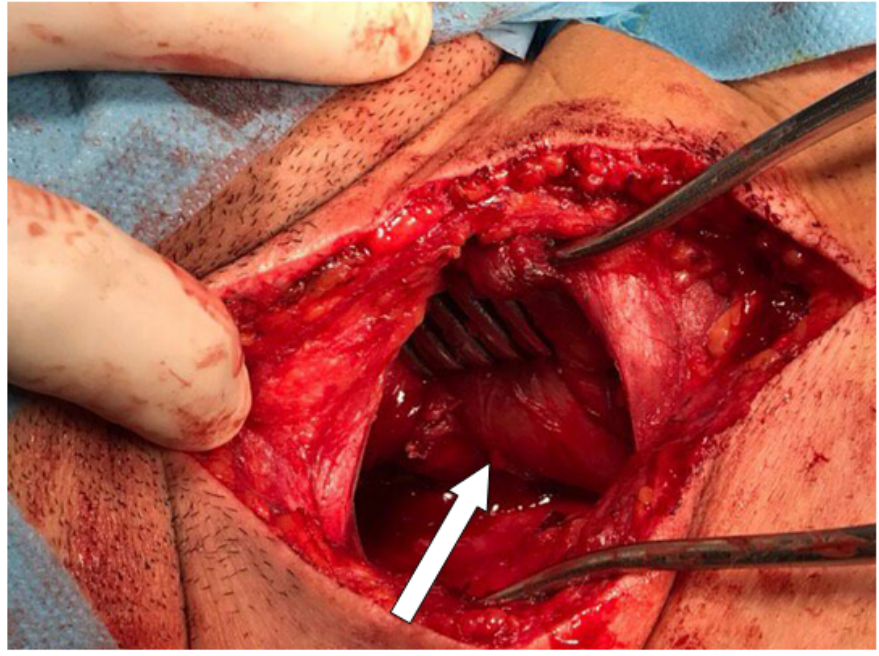

Figure 4. Left posterolateral thoracotomy showing the left subclavian artery aneurysm (White arrow)

\section{Discussion}

Hemoptysis has been defined as the coughing up of pure blood or blood mixed with mucus from the trachea, larynx, bronchi or lungs. In the current case, the source of bleeding was from lower trachea [6]. The condition may be the only presentation or complication of different respiratory diseases including pulmonary carcinoma, infections such as bronchitis, tuberculosis or pneumonia, and some cardio-vascular diseases. In this case, there was not any underlining pulmonary diseases [7]. In massive hemoptysis (hemoptysis more than $300 \mathrm{cc}$ of blood expectoration) physician should think of severe underlining injuries. In this situation, the most striking danger does not come from exsanguinations but from choking. On presentation, our case was about to suffocate, $\mathrm{SPO} 2$ was $69 \%[8,9]$.

Valentine Mott is the one that has been credited with the first tried surgical management of subclavian artery aneurysm in almost one century ago (1918). However, the patient did not make it and died from sepsis and hemorrhage. About twelve decades later, A.W Smyth did the first proximal tie successfully for an aneurysm of the subclavian artery [10]. Aneurysm of subclavian artery is extremely rare with only a few small case series and reports could be found in the current literature. This makes the managing physician hardly think of this disease and the patients become tired from visiting and admitting to different hospital and frequent investigations [5]. Our case was diagnosed as a case of subclavian aneurysm after 20 days of hospitalization and remained in hospital for about 25 days. Aneurysm of the subclavian artery may remain asymptomatic for several years, especially when intrathoracic intrathoracic part affected [10]. The most frequently reported signs and symptom are shoulder or chest. It could present as a supraclavicular pulsatile swelling. In rare instance, neurological symptoms may also occur for long period of time. The current case was completely normal before 2 days and presented with massive hemoptysis which is the first time to be reported in the literature. History of tuberculosis before one year was not found to be related to the current situation in our case [10].

\section{Conclusion}

Massive hemptysis is a life-threatening condition. Subclavian aneurysm-tracheal fistula presenting with massive hemoptysis has been 
Falsk L (2018) Subclavian aneurysm-tracheal fistula presenting with massive hemoptysis, a diagnostic dilemma to the emergency room personnel - A case report

reported for the first time in the literature. It presented as a diagnostic dilemma to the emergency room personnel.

\section{References}

1. Torikai H, Hasegawa I, Jinzaki M, Narimatsu Y (2017) Preliminary experience of endovascular embolization using N-butyl cyanoacrylate for hemoptysis due to infectious pulmonary artery pseudoaneurysms via systemic arterial approach. $J$ Vasc Interv Radiol 28: 1438-1442. [Crossref ]

2. Okuda K, Tanaka J, Okamoto J, Kishi F, Nakagawa J, et al. (2017) Two cases of cryptogenic life-threatening hemoptysis-identification and management of bleeding point. Acute Med Surg 4: 114-118. [Crossref]

3. Flume PA, Mogayzel Jr PJ, Robinson KA, Rosenblatt RL, Quittell L, et al. (2010) Cystic fibrosis pulmonary guidelines: pulmonary complications: hemoptysis and pneumothorax. Am J Respir Crit Care Med 182: 298-306. [Crossref]

4. Sakr L, Dutau H (2010) Massive hemoptysis: an update on the role of bronchoscopy in diagnosis and management. Respiration 80: 38-58. [Crossref]
5. Kochupura PV, Greelish JP (2016) Staged hybrid repair of an intrathoracic subclavian artery aneurysm associated with a long segment dissection. Ann Vasc Surg 306: e1-e3. [Crossref]

6. Gaude GS (2010) Hemoptysis in children. Indian Pediatr 47: 245-254. [Crossref]

7. Yoo DH, Yoon CJ, Kang SG, Burke CT, Lee JH, et al. (2011) Bronchial and nonbronchial systemic artery embolization in patients with major hemoptysis: safety and efficacy of N-butyl cyanoacrylate. AJR Am J Roentgenol 196: W199-204. [Crossref ]

8. Woo S, Yoon CJ, Chung JW, Kang SG, Jae HJ, et al. (2013) Bronchial artery embolization to control hemoptysis: comparison of N-butyl-2-cyanoacrylate and polyvinyl alcohol particles. Radiology 269: 594-602. [Crossref]

9. Woo S, Yoon CJ, Chung JW, Kang SG, Jae HJ, et al. (2013) Bronchial artery embolization to control hemoptysis: comparison of N-butyl-2-cyanoacrylate and polyvinyl alcohol particles. Radiology 269: 594-602. [Crossref ]

10. Maskanakis A, Patelis N, Moris D, Tsilimigras DI, Schizas D, et al. (2018) Stenting of subclavian artery true and false aneurysms: a systematic review. Ann Vasc Surg 47: 291-304. [Crossref]

Copyright: C2018 Falsk L. This is an open-access article distributed under the terms of the Creative Commons Attribution License, which permits unrestricted use, distribution, and reproduction in any medium, provided the original author and source are credited. 